\title{
Iniciação ao violão por meio de práticas musicais coletivas: aspectos para a produção de arranjos didáticos
}

Initiation with guitar by musical collective: didactic application of a model for arrangements

Tamires Rampinelli ${ }^{1}$ tarampinelli@gmail.com

Clayton Daunis Vetromilla cvetromilla@gmail.com 


\section{Resumo}

Este estudo apresenta aspectos do projeto de pesquisa que está sendo desenvolvido no Programa de Mestrado Profissional em Música (Proemus) da Universidade Federal do Estado do Rio de Janeiro (Unirio). Depois de breve categorização de uma amostragem da produção pedagógica de violonistas brasileiros renomados (ZANON, 2006), discutimos aspectos pertinentes à elaboração de arranjos didáticos visando o contexto de aulas coletivas de instrumento. Finalmente, são apresentadas duas versões instrumentais para a canção folclórica $O$ cravo brigou com a rosa, que contemplam os temas discutidos anteriormente. Do ponto de vista teórico, confrontamos França e Swanwick (2002) ao propor um estudo da performance instrumental que contempla criatividade, expressividade e consistência estilística.

Palavras-chave: Iniciação ao violão; Práticas musicais coletivas; Arranjos didáticos; Processo de musicalização através do violão

\section{Abstract}

This study aims to present aspects of the research project, which is being developed in the Master's Program in Music (Proemus) of the Federal University of the State of Rio de Janeiro (Unirio). After creating categories of the pedagogical production of Brazilian guitarists (Zanon, 2006), we approached aspects about the elaboration of arrangements for collective musical study of the instrument. Finally, it presents a guitar arrangement for a Brazilian song "O cravo brigou com a rosa", by using the fundamental aspects addressed by the text. From a theoretical point of view, we discuss France; Swanwick (2002) proposing an instrumental performance study that contemplates creativity, expressiveness and consistency over style.

Keywords: Initiation with guitar; collective musical; guitar arrangement; music and education by guitar.

\footnotetext{
1 Graduada em Música pela Universidade Federal de São João Del-Rei (2017). Mestranda em Música na Universidade Federal do Estado do Rio de Janeiro. Tem experiência na área de Artes, com ênfase em Música, atuando principalmente nos seguintes temas: violão, performance e educação musical.

2 Professor no Instituto Villa-Lobos da Universidade Federal do Estado do Rio de Janeiro (RJ, 2004). Doutor em Música pelo Programa de Pós-Graduação em Música da Unirio (2011), com estágio de doutoramento (bolsa Capes - PDEE) na Universidade de Aveiro, Portugal. Mestre em Música pela UFRJ e bacharel em Violão pela UFMG. Trabalhou com o compositor Rufo Herrera, do qual estreou várias obras. Como intérprete e pesquisador, desenvolve trabalhos principalmente em relação às obras de Heitor Villa-Lobos e César Guerra-Peixe, bem como sobre a música erudita brasileira para violão dos anos 1970.
} 


\section{Introdução}

Este estudo apresenta aspectos do projeto de pesquisa que está sendo desenvolvido no Programa de Mestrado Profissional em Música (Proemus) da Universidade Federal do Estado do Rio de Janeiro (Unirio). Em linhas gerais, o trabalho reflete sobre a dimensão pedagógica do fazer musical coletivo e seu papel na educação musical, em particular sobre o ensino-aprendizagem instrumental. Para tal, inicialmente, refletimos sobre os métodos de ensino de violão tradicional, partindo de Zanon (2006).

Além de abordar a chegada do violão ao Brasil, a trajetória de intérpretes e compositores renomados, bem como obras emblemáticas do repertório, o estudioso destaca a presença de cinco pedagogos cujos trabalhos contribuíram para o aprimoramento da formação de violonistas e, por conseguinte, para a visibilidade do instrumento no âmbito da cultura brasileira. Em tal contexto, Fábio Zanon considera "a importante contribuição" de Attilio Bernardini, cuja consequência mais visível ocorreu "no campo do violão popular"; de Isaías Sávio, que "foi um concertista de modestos recursos, mas um devotado professor e autor de mais de 100 peças originais para violão"; e de Antônio Rebello, destacado discípulo de Sávio que atuou no Rio de Janeiro; bem como de "uma nova geração de didatas" que se estabeleceu na década de 1970, destacando Henrique Pinto e Jodacil Damaceno (Zanon, 2006, p.80-82). Em certa medida, o autor calcula a importância do legado deixado por tais professores devido à projeção nacional e internacional alcançada por seus discípulos na carreira como concertistas.

Aqui, realizamos um levantamento sumário de publicações assinadas por Bernardini, Sávio, Rebello, Pinto e Damaceno que podem ser situadas entre métodos de violão, conforme as vertentes identificadas por Nicácio (2012). Em seguida, discutimos aspectos pertinentes à elaboração de arranjos didáticos (nomeadamente, leitura musical e técnica violonística), visando o contexto de aulas coletivas de instrumento, partindo da análise descritiva das primeiras "lições" de uma amostragem do material anteriormente selecionado. Por fim, apresentamos duas versões instrumentais (para três e cinco violões, respectivamente) da canção folclórica $O$ cravo brigou com a rosa, como exemplo do que denominamos como "arranjos didáticos", não somente por contemplarem habilidades técnicas específicas, mas também por considerarem uma prática de conjunto que integra estudantes cujo grau de conhecimentos teóricos tende a ser heterogêneo.

Do ponto de vista teórico, confrontamos França e Swanwick (2002) ao propor um estudo da performance instrumental que contempla criatividade, expressividade e consistência estilística. Consideramos que "um objetivo básico da educação musical é o desenvolvimento de uma apreciação rica e ampla quer o aluno se torne um músico profissional, um amador talentoso ou um membro sensivel de plateias" (SWANWICK, 1993, p.29). Ou seja, ao chegarem em um ambiente formal, não formal ou informal de ensino-aprendizagem de música (SALUSTINO, 2013, p.13-17), os interessados carregam consigo uma experiência significativa em relação à música. 
Ou seja, conforme afirmou Swanwick em outra ocasião, eles (os estudantes) possuem "domínio de compreensão musical" e estão "bem familiarizados com ela", cabendo à figura do professor respeitar seu desenvolvimento, sua autonomia e sua espontaneidade, que se manifestam por meio de "curiosidade; desejo de ser competente; querer imitar outros; necessidade de interagir socialmente" (2003, p.66). Ocorre, contudo, que França e Swanwick (2002) fazem uma distinção entre a natureza e os objetivos da educação musical em geral e do "ensino musical especializado", onde se situa a "performance instrumental", considerada como um padrão referencial para a "realização musical" $(2002$, p.8). Os autores se baseiam em diversas pesquisas para comprovar a tese segundo a qual "o ensino tradicional da performance instrumental tende a priorizar o desenvolvimento técnico instrumental e a tradição musical escrita" (2002, p.13).

Aqui, defendemos a possibilidade de "um fazer musical mais abrangente, com oportunidades para decisão criativa e exploração musical expressiva" (FRANÇA; SWANWICK, 2002, p.13), no âmbito do ensino-aprendizagem coletivo do instrumento. Para tal, fomentamos a elaboração de arranjos didáticos que consideram a multiplicidade de interesses e de níveis de um grupo de estudantes envolvidos com a música e, em particular, com o desejo de tocar violão. Ou seja, o processo de ensino coletivo do violão pode propiciar resultados, ao mesmo tempo, criativos, expressivos e estilisticamente consistentes.

\section{Métodos de violão publicados no Brasil: esboço preliminar para uma tipologia}

Conforme Harder (2008), na segunda metade do século XIX, "O advento dos métodos impressos levou a performance musical a se tornar uma arte mais reprodutiva, com menos ênfase na criação e ênfase excessiva no desenvolvimento de habilidades técnicas", abrindo caminho para os grandes e aclamados virtuoses (p.133). No âmbito do ensino do violão, destacam-se, entre outros, os trabalhos de Ferdinando Carulli (17701841) (Método para Guitarra, de 1810, o livro Harmonia aplicada à Guitarra, de 1825) e de Fernando Sor (1778-1839) (Método para Guitarra, de 1830) (CARVALHO, 20133). A necessidade de ampliar e difundir materiais pedagógicos elaborados para servirem de suporte teórico e metodológico, auxiliando o professor de instrumento em seu trabalho, é uma demanda constante (HARDER, 2008, p.135).

No caso do Brasil, dos autores citados por Zanon (2006), por meio de levantamento bibliográfico, localizamos até o presente momento três publicações de Attilio Bernardini (1888-1975) que podem ser situadas como métodos de ensino-aprendizagem do violão. São elas Ensaios de Harmonia e Violão, de 1927, Método prático para violão Giannini, de 1942, e Lições preparatórias, também de 1942. De Isaías Sávio (1900-1977), 
por outro lado, entre várias outras publicações, destacamos Escola moderna do violão, vol. 1, de 1947; Escola moderna do violão, vol. 2, de 1961; Vamos estudar violão, de 1972; Efeitos violonísticos e modo de execução dos ornamentos musicais, de $1973^{4}$.

Sabemos que Antônio da Costa Rebello (1902-1965) estudou com Isaías Sávio, contudo, até o presente momento, não localizamos publicações ou estudos específicos sobre seu legado pedagógico. Alfonso (2009), entretanto, além de compilar testemunhos de Damaceno (que estudou com Rebello entre 1952 e 1960), faz pressupor a existência de um acervo considerável de documentos (partituras, gravações, anotações etc.) que podem vir a trazer luz sobre a trajetória do professor de renomados violonistas, como Turíbio Santos, além dos irmãos Sérgio e Eduardo Abreu, entre outros. De Jodacil Caetano Damaceno (1929-2010), conhecemos Uma sugestão para iniciação ao violão, de 2010, e Elementos básicos para a técnica violonística, de 2011, ambos escritos em parceria com, respectivamente, André Campos Machado e Saulo S. Alves Dias.

Finalmente, dos nomes citados por Zanon (2006), Henrique Pinto (1941-2010) foi autor de uma produção pedagógica - Iniciação ao violão, de 1978; Ciranda das seis cordas, de 1985; Técnica da mão direita, de 1985; e Iniciação ao violão, vol. 2, de 1999 - que, juntamente com a da Sávio, permanece como referência na formação de violonistas da atualidade. Neste contexto, devemos lembrar que, a partir da década de 1940, o ensino do violão no Brasil foi sendo formalizado paralelamente ao processo de afirmação do repertório do instrumento no âmbito da música de concerto. Assim, se, de um lado, Sávio desempenhou "um papel considerável na promoção do violão dentro do establishment musical do país" (ZANON, 2006, p.81), de outro, certamente, das personalidades aqui mencionadas, Damaceno teve uma atuação preponderante para a oficialização do ensino do instrumento nos cursos superiores, que veio ocorrer na década de 1970 (ALFONSO, 2009, p.117-135).

Ou seja, as publicações aqui examinadas se situam em um campo que tende a reproduzir, de maneira mais ou menos adaptada, a metodologia e o repertório europeu consagrado do século XIX (DUDEQUE, 1994) ${ }^{5}$. Por exemplo, a crítica situa Bernardini, Sávio, Rebello e Damaceno como continuadores do legado da técnica desenvolvida pelo violonista espanhol Francisco Tárrega (1852-1909), cujos princípios nortearam a formação dos grandes violonistas que circulavam nas salas de concerto brasileiras desde a década de 1940 (BARTOLONI, 1995). Numa outra corrente, situa-se Pinto, que é considerado como "um dos primeiros professores brasileiros a adotar e difundir a obra e a escola do didata uruguaio Abel Carlevaro (1916-2001)" (TEIXEIRA NETO, 2000, p.3233), e que, provavelmente, é o pedagogo que deixou mais amplamente difundida sua concepção a respeito do ensino-aprendizagem do instrumento formalizada no texto "Violão, um olhar pedagógico", de 2005.

\footnotetext{
4 Para uma lista mais ampla da obra pedagógica de Sávio, ver Orosco (2001).

5 Para uma análise comparativa dos principais métodos do período, ver Cardoso (2015).
} 
Evidentemente, tal amostragem de autores e de publicações não contempla a dimensão da produção brasileira visando o ensino-aprendizagem do violão, contudo, uma breve análise do referido material permite-nos identificar uma categorização esboçada por Nicácio (2012). Conforme o referido estudioso, há duas vertentes básicas entre os métodos de violão: os "métodos práticos" e os "métodos por música". Nos primeiros ("métodos práticos") são apresentadas, por meio de diagramas, sequências harmônicas (acordes nomeados por "cifra") organizadas conforme as diferentes tonalidades (CORREA, 2015). Tais trabalhos remontam ao pioneiro Instruccion de musica sobre la guitarra española, vol. 2, de Gaspar Sanz (1640-1710), em particular na seção que trata das "cifras" (AFFONSO, 2015), carecendo, contudo, das "regras" para o acompanhamento, à maneira que aparece no trabalho do autor espanhol.

$\mathrm{Na}$ amostragem aqui examinada, um exemplo de "método prático" é o Método prático para violão Giannini, de Bernardini. Poderíamos incluir neste mesmo perfil de trabalho inúmeras publicações de violonistas renomados no campo da música popular. Por exemplo, de Canhoto (Américo Jacomino, 1887-1928), o Manual de violão de Américo Jacomino, Canhoto; de Garoto (Aníbal Augusto Sardinha, 1915-1955), o Cacique: método prático para violão e, de Dilermando Reis (1917-1977), o Método para violão prático do professor Dilermando Reis.

Conforme Nicácio (2012), os "métodos por música" podem ser divididos em três subgrupos: "de musicalização", "de iniciação" e "de aperfeiçoamento". Os "métodos de musicalização" se propõem a trabalhar concomitantemente noções básicas de teoria da música (pauta musical, valores etc.) e de técnica do violão. Assim, por meio da profusão de recursos gráficos e pedagógicos pertinentes normalmente ao universo infantil, tais trabalhos objetivam introduzir o estudante no campo da linguagem musical e, ao mesmo tempo, da prática violonística (SILVA, 2013) ${ }^{6}$. Na amostragem aqui examinada, encontramos exemplos desta vertente em Vamos estudar violão, de Sávio, e Ciranda das seis cordas, de Pinto, que podem ser considerados pioneiros em nível nacional.

Os "métodos por música", aqui situados como "de iniciação", pressupõem algum grau de musicalização dos interessados, partindo diretamente para a aplicação destes conhecimentos na leitura de exercícios (para o aprendizado da técnica básica do instrumento) e de repertório original (isto é, peças didáticas escritas pelo próprio autor do método) ou de compositores dos períodos Clássico e Romântico (Fernando Sor e Francisco Tárrega, por exemplo). Da amostragem aqui estabelecida, encontramos exemplos desta vertente em Lições preparatórias, de Bernardini; Escola moderna do violão, vol. 1, de Sávio; Iniciação ao violão, de Pinto; e Uma sugestão para iniciação ao violão, de Damaceno e Machado. Os métodos "de aperfeiçoamento" normalmente dão continuidade a um volume anterior ou abordam questões específicas da técnica violonística.

No primeiro caso, situam-se Escola moderna do violão, vol. 2, de Sávio; Elementos básicos da técnica violonística, de Damaceno e Dias; e Iniciação ao violão, vol. 2, de Pinto, embora o último se constitua, na prática, como uma antologia de peças de autores clássicos. Em Sávio e Damaceno, considerando que o estudante domina a técnica geral 
do violão, são apresentados exercícios que abordam especificidades mais complexas do ponto de vista da realização instrumental (escalas, arpejos e ligados mecânicos, por exemplo), recorrentes em um repertório de nível intermediário. Em outra vertente, Técnica da mão direita, de Pinto, aborda um aspecto específico (no caso, os arpejos "de mão direita"), buscando explorá-lo em suas diferentes possibilidades de aplicação no repertório.

Vale acrescentarmos que os títulos examinados até aqui se inserem nas fases de reconhecimento e de afirmação do violão na cultura brasileira, em particular, no que diz respeito ao seu potencial expressivo no âmbito da música erudita. Com exceção de Bernardini, mas incluindo métodos de musicalização infantil por meio do violão, observamos que tais trabalhos se caracterizam pela ênfase que conferem à música "de concerto" e à prática de um repertório solista. Neste contexto, embora próximo da tradição do ensino violonístico que remonta à "Escola de Tárrega", o trabalho de Damaceno e Machado (2010) explicita a possibilidade não somente do canto acompanhado de canções populares e folclóricas, mas também de práticas coletivas de estudo, por meio de duos e trios ${ }^{7}$.

\section{Aspectos do estudo do violão e a prática musical coletiva: prelimi- nares para uma noção de "arranjo didático"}

No campo dos métodos de iniciação "por música", consideramos duas questões básicas, aqui relacionadas entre si: leitura musical e técnica violonística. A primeira evidencia-se nos métodos "de iniciação", que pressupõem como pré-requisito o domínio da leitura da partitura musical (pauta musical, linhas suplementares inferiores, clave de sol, notas naturais, compassos simples, figuras de duração e silêncio) (Fig. 1). Neste contexto, a partitura pode ser considerada como uma "representação simbólica", de grande utilidade para "o registro, previsão e comunicação, permitindo fixar o texto musical e repeti-lo, além de ajudar a perceber sua estrutura e organização" (PENNA, 2008, p.51).
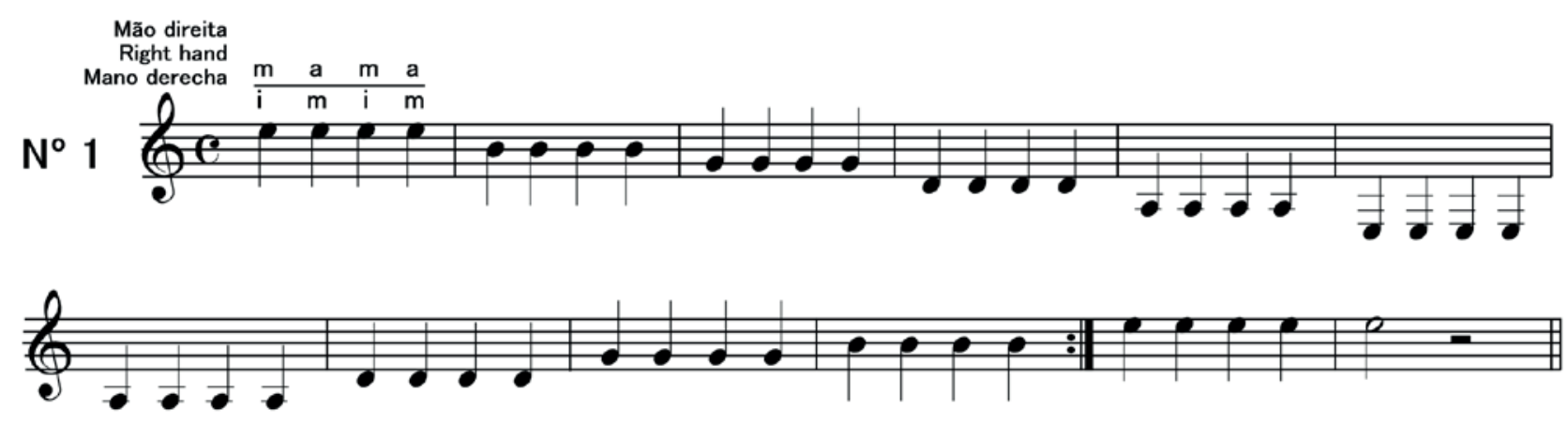

Fig. 1: Exemplo de um exercício inicial, que implica o conhecimento das notas na pauta musical e sua correspondente localização no violão (as seis cordas do violão previamente afinadas) (SÁVIO, 1947, p.11). 
Os métodos de "musicalização através do violão" situam-se como uma vertente paralela que busca aliar concomitantemente noções de teoria musical e sua aplicação na prática do instrumento (Fig. 2). Por exemplo, Mesquita (2015), ao comparar Iniciação ao violão e Ciranda das seis cordas, ambos de Pinto, com $O$ equilibrista das seis cordas (MARIANI, 2009), considera que, em tese, todos os três possuem como objetivo geral a iniciação progressiva à leitura musical em paralelo com "desenvolver habilidades motoras e domínio progressivo e por etapas no modo de executar o instrumento" (MESQUITA, 2015, p.8). Porém, ao confrontar as especificidades extrínsecas e intrínsecas de Iniciação ao violão com $O$ equilibrista das seis cordas, o mesmo autor reconhece que, de um lado, Mariani (2009) "trabalha recursos gráficos" explorando diferentes possibilidades sonoras que o violão oferece; de outro lado, Pinto (1978) se concentra no repertório, "sem se preocupar com o desenvolvimento teórico-prático do aluno, o que deverá ser desenvolvido [com o auxílio do] professor" (MESQUITA, 2015, p.30).

7. Etapa

\section{EU SOU A NOTA FÁ}

1. ${ }^{\circ}$ ) Identificar e solfejar.

2. ${ }^{\circ}$ ) Tocar a nota pronunciando seu nome.
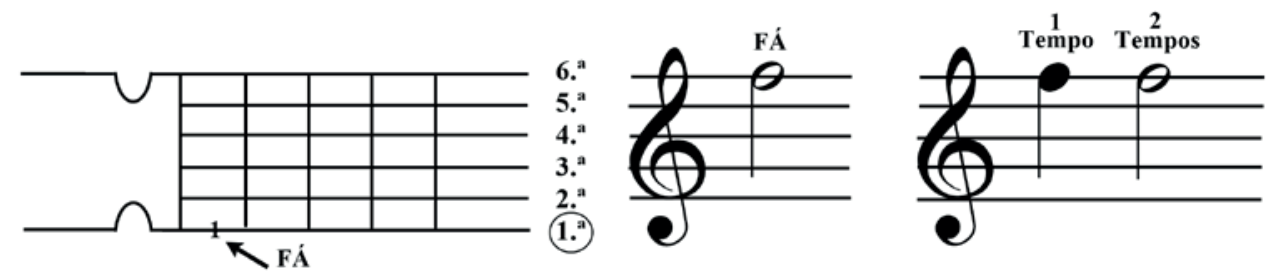

Fig. 2: Localização da nota Fá no braço do violão e na pauta musical, além das figuras de duração ("contando os tempos") semínima e mínima apresentadas anteriormente (PINTO, 1985, p.12).

Aqui, é necessário ponderarmos que Mesquita (2015) desconsidera a possível distinção apresentada por Nicácio (2012), que identifica, entre os "métodos por música", aqueles de "iniciação ao violão" e de "musicalização através do violão". Neste contexto, seria possível explicar o referido afastamento entre a proposta de Pinto (1978) e Mariani (2009), bem como certa proximidade entre Pinto (1985) e Mariani (2009), devido aos pressupostos metodológicos explícitos. Os primeiros, de "iniciação ao violão", em seguida, de "musicalização através do violão".

O trabalho de Mariani aponta que as fases iniciais do aprendizado do violão são propícias para explorar timbres e efeitos (harmônicos naturais, pizzicato ou efeitos percussivos, entre outros) que, além de ampliarem as possibilidades técnicas do estudante, propiciam desenvolver sua percepção e critérios estéticos (2009, p.118). Por exemplo, o Exercício da impaciência possui uma dupla função (p.51), pois, ao mesmo tempo que desenvolve a consciência corporal, descortina uma sonoridade percussiva característica; enquanto Descobrindo sons no violão apresenta noções básicas de como realizar ao violão diversos efeitos, como o pizzicato e glissandos (p.61). Cabe ressaltarmos que a 
mesma autora incentiva, durante todo o decorrer do processo de aprendizado, práticas musicais coletivas, incluindo propostas específicas, como, por exemplo, Tocando com dois violões (p.48) ou Tocando com três violões (p.64).

A segunda questão aqui considerada (técnica violonística) recoloca o tema das vertentes pedagógicas acima mencionadas por Bartoloni (1995) e Teixeira Neto (2000). Nas fases preliminares do ensino do violão, os pedagogos ligados à tradição da Escola de Tárrega (Bernardini e Sávio, por exemplo) apresentam, invariavelmente, exercícios cuja finalidade é extrair o som do violão através da alternância dos dedos indicador e médio (posteriormente, dedos médio e anelar) da mão direita, que pinçam cada qual uma única nota obtida em alguma das seis cordas do violão previamente afinado (Fig. 2), como que preparando a execução de melodias (Fig. 3). De outro lado, os pedagogos ligados à Escola de Carlevaro (Pinto, por exemplo), adotam - logo de início - o viés segundo o qual os dedos da mão direita (polegar, indicador, médio e anelar) pousam concomitantemente sobre as cordas o violão, como que preparando a execução de acordes (Fig. 4).

\section{EXERCICIOS NUMA CORDA}

$17^{\circ} \cdot 2$

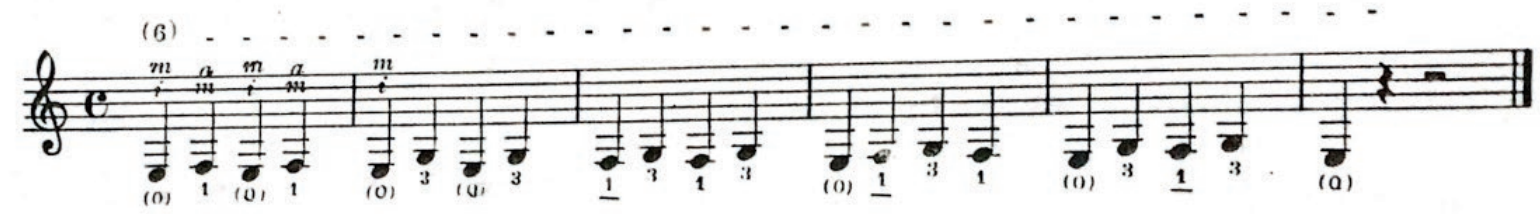

$96 m$

Fig. 3: Exemplo de um exercício a ser executado pressionando os dedos da mão esquerda sobre o braço do violão (para se obter as notas Fá e Sol), alternando invariavelmente os dedos indicador (i) e médio (m) (posteriormente, também médio [m] e anelar [a]) para pinçar a $6^{\mathrm{a}}$ corda (BERNARDINI, 1942, p.6).

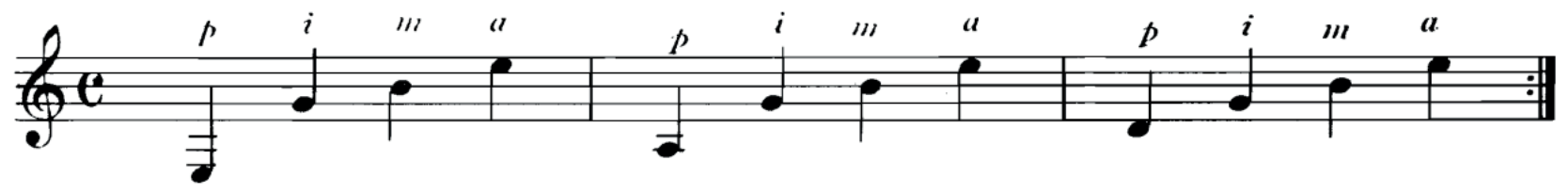

Fig. 4: "Terceiro exercício: combinação do dedo polegar com indicador, médio e anelar" apresentado por Pinto (1978, p.6) depois de uma série de exercícios preparatórios (p.17-20). Observamos que os dedos polegar (p), indicador (i), médio (m) e anelar (a) pinçam as cordas em uma sequência contínua, sendo que o polegar alterna-se entre a $6^{\mathrm{a}}$, $5^{\mathrm{a}}$ e $4^{\mathrm{a}}$ cordas.

Do ponto de vista da técnica violonística, neste caso, devemos considerar o desenvolvimento de duas habilidades distintas. A primeira, executar melodias, o que implica, basicamente, a alternância dos dedos indicador e médio da mão direita em combinação com os dedos da mão esquerda, que pressionam as cordas sobre o braço do violão para 
obter as notas que não fazem parte da afinação natural do instrumento. A segunda traz a possibilidade de executar acordes, o que implica, basicamente, a execução de um padrão rítmico pelos dedos da mão direita em combinação com a execução de acordes pela mão esquerda.

Em linhas gerais, observamos, portanto, que os métodos de iniciação ao violão "por música", nas fases iniciais, utilizam-se da pauta musical como mediadora para fixar e transmitir exercícios básicos, que permitem ao estudante produzir o som do instrumento por meio do pinçar as cordas com a mão direita, primeiramente, sem utilizar os dedos da mão esquerda para pressioná-las (como na Fig. 1), e, em um segundo momento, utilizando-os (como na Fig. 2). Ao mesmo tempo, à médio prazo, o domínio da leitura musical será uma ferramenta essencial para a transmissão do repertório pertinente às fases mais avançadas.

Aqui, vale ressaltarmos o trabalho de Rocha Filho (1966), que buscou um equilíbrio ao inerir em seu trabalho obras dos "Grandes mestres do violão" (Tárrega, Sor, Carulli, entre outros) (p.74-86) e músicas folclóricas (p.56-60), além de noções de acompanhamento por meio do estudo das "cifras" (p.32-34) e "Ritmos diversos (para acompanhamento) " (canção, baião, samba-bossa nova, entre outros) (p.87-94), congregando aspectos dos "métodos práticos". Tal proposta se fez presente também em Damaceno e Machado (2010), que incorporam a noção de "acompanhamento", ou seja, desenvolver as habilidades de executar uma sequência de acordes (pressionando os dedos da mão esquerda sobre as cordas do instrumento) e de manter o padrão rítmico ("levada") (pinçando as cordas do violão com os dedos da mão direita).

De tal ponto de vista, de certa maneira, podemos considerar os "métodos práticos" como um caso particular dos "métodos de aperfeiçoamento", que tratam dos acordes ou, mais genericamente, do estudo da harmonia. Consequentemente, trabalhos como Ritmos brasileiros, de Marco Pereira; 211 levadas rítmicas: para violão e outros instrumentos de acompanhamento, de Renato de Sá; e Levadas brasileiras para violão, de José Paulo Becker, podem ser considerados como uma espécie de catálogo, ou antologia, dos padrões rítmicos (ostinatos) que reproduzem, ao violão, características de diferentes gêneros musicais, como, por exemplo, baião, samba e valsa. Ou seja, percebemos uma certa complementaridade entre os "métodos práticos" e os catálogos de "Levadas".

Diante de tais ponderações, coloca-se o principal objeto de nossa pesquisa, propor modelos de "arranjos didáticos" que propiciem a prática musical coletiva, integrando o aprendizado de noções de leitura e escrita musical, bem como de princípios da técnica básica do violão. Ou, como França e Swanwick atribuem à educação musical, visamos "desenvolver habilidades motoras, perceptivas e notacionais" $(2002$, p.14) dos estudantes. Para desenvolver o projeto, adotamos um viés semelhante ao de Machado (2007) e de Riccio (2018).

O primeiro buscou "contribuir para o aumento de repertório para alunos em sua fase inicial de aprendizado violonístico" (p.11), apresentando uma seção "para o estudo e a prática do [violão] em grupo" que contém duas peças originais (Valsa $n$ o 1 e Pequeno concerto para grupo de violões) e um arranjo (Villano, de Gaspar Sanz, baseado na 
versão do compositor espanhol Joaquin Rodrigo) (p.33-64). O segundo elaborou uma coleção de arranjos coletivos para grupos de violões que, em linhas gerais, constituem-se numa parte solista (baseada em melodias folclóricas), para ser tocada e/ou cantada, e acompanhamento, constituído por percussão, arpejos e baixo. Riccio, depois de trabalhar o repertório em formato camerístico, reapresenta o mesmo material em arranjos para violão solo (2018, p.55-65), ou seja, de certa maneira, há uma opção consciente por desenvolver a percepção do coletivo e do polifônico (as diferentes vozes ou planos sonoros) como pressuposto para a música "solista".

A proposta que aqui defendemos amplia tais possibilidades ao ponderar que "a execução de um repertório de interesse dos alunos tem influenciado diretamente o desempenho musical dos estudantes e sua motivação para continuar aprendendo o instrumento" (OLIVEIRA, 2014, p.1). Conforme Oliveira, que segue a mesma linha de raciocínio de Tourinho (2009), não cabe ao professor impor ou julgar as qualidades estéticas do repertório, mas, sim, analisar a possível contribuição que o material pode trazer à vivência musical dos estudantes. Ou seja, o potencial pedagógico da proposta aqui defendida está em relação direta com o interesse dos estudantes em executar um repertório instigante do ponto de vista estético, adequado quanto às exigências de execução (técnica violonística) e desafiador no sentido de decodificar os elementos gráficos da escrita musical.

Como se não bastasse, o ensino coletivo é "uma importante ferramenta para o processo de socialização do ensino de música", pelo fato de potencializar a democratização do acesso à formação musical "através da motivação e interação social" (VIEIRA; RAY, 2007, p.2). Entendemos que um arranjo é definido, em linhas gerais, pela inserção e reestruturação de novos elementos a uma partitura (ou versão) preexistente de determinada música. Ou seja, consideramos que um "arranjo musical" consiste, basicamente, "em reescrever uma obra musical dando a esta um caráter diferente da proposta original, destinando-a a formações vocais ou instrumentais organizadas de acordo com os recursos disponíveis, tais como a instrumentação e habilidade dos músicos" (VIEIRA; RAY, 2007, p.9).

\section{Ocravo brigou com a rosa: arranjo didático instrumental (duas versões)}

A finalidade dos arranjos aqui apresentados é artística e, concomitantemente, didática, por levar em conta premissas "relacionadas tanto com o grau de dificuldade técnica do arranjo quanto com o material explorado ou utilizado para a sua realização" (LIMA, 2003, p.34). Apresentamos adiante os princípios que nortearam duas versões para um arranjo didático instrumental da melodia de tradição oral $O$ cravo brigou com a rosa (PAZ, 2009, p.88). Para a elaboração de ambas, consideramos a possibilidade de estar trabalhando com grupos heterogêneos quanto aos seus conhecimentos teóricos sobre música e quanto às suas habilidades ao violão. 
Portanto, as três esferas apresentadas fazem coincidir, de um lado, os planos sonoros presentes no arranjo (melodia, harmonia e percussão) e, de outro, o grau de conhecimento ou as habilidades necessárias (avançado, intermediário e iniciante) para executá-los. Nos métodos de violão "por música" aqui examinados, os primeiros contatos do estudante com a sonoridade do violão ocorrem através do pinçar com os dedos da mão direita as cordas do instrumento previamente afinado. Isso ocorre mediante a alternância dos dedos indicador e médio da mão direita ou mediante a realização de arpejos nos quais cordas contíguas são pinçadas pelos dedos polegar, indicador, médio e anelar (mão direita).

Neste caso, os dedos da mão esquerda não são utilizados para pressionar as cordas, limitando as possibilidades melódico-harmônicas às combinações entre as notas Mi 4 (primeira corda), Si 3 (segunda corda), Sol 3 (terceira corda), Ré 3 (quarta corda), Lá 2 (quinta corda), Mi 2 (sexta corda). A proposta que desenvolvemos se baseia em Mariani (2009) não somente para incorporar as noções de pulsação rítmica e altura (grave e agudo), mas também para explorar sonoridades alternativas. Assim, em $O$ cravo brigou com a rosa: arranjo didático (versão I e II), a parte "iniciante" explora efeitos percussivos (percussão).

Oriundos da "técnica estendida", gradativamente certos efeitos percussivos têm se incorporado à técnica ordinária do violão. Evidentemente, a ideia de uma técnica não usual, em tese, se modifica ao longo do tempo, assim, conforme Vasconcellos (2013, p.15), no caso do violão, por exemplo, há diversos elementos que foram considerados inovadores, mas, paulatinamente, acabaram se incorporando à técnica tradicional. Por exemplo, percutir com os dedos da mão direita em diferentes regiões do corpo do violão, explorando novas sonoridades (Fig. 5).

\section{PERCUSSION SECTION}

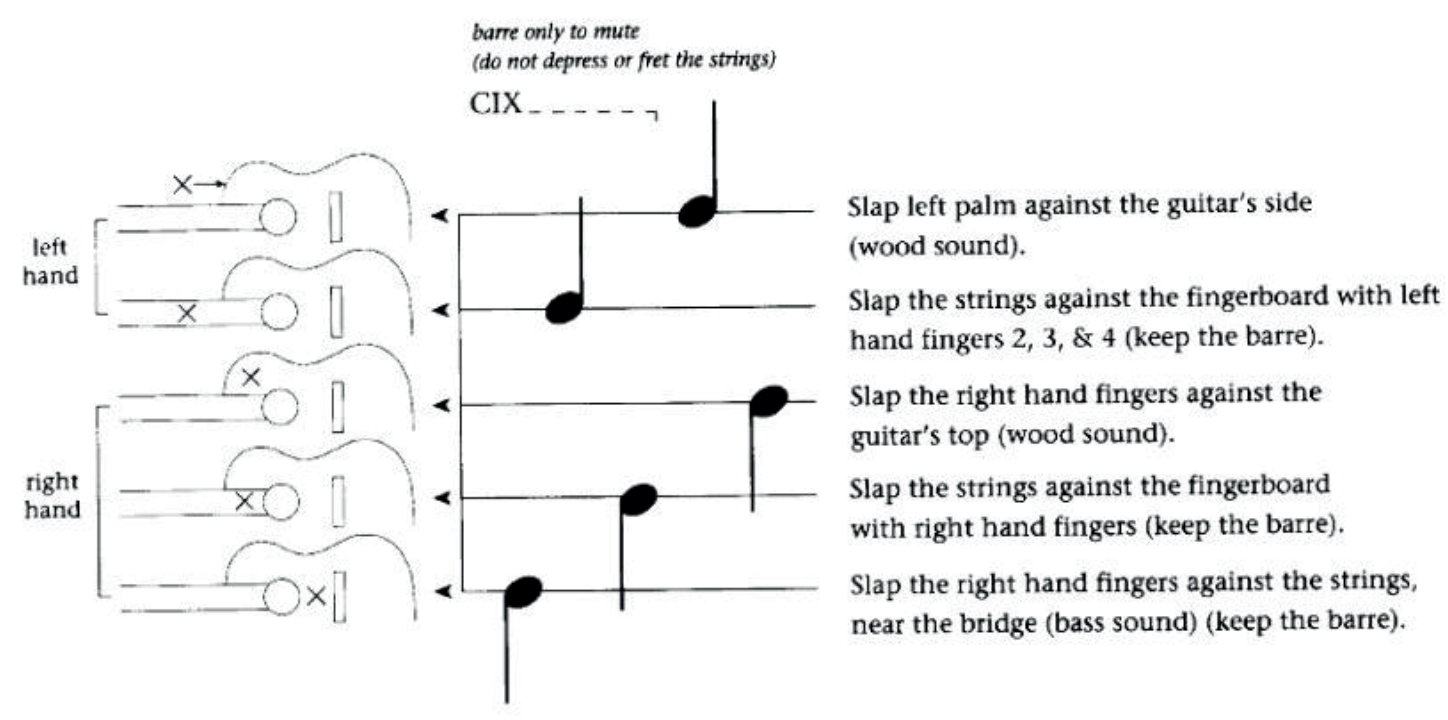

Fig. 5: Bula para a sessão percussiva da obra Jongo (BELLINATI, 1993). 
Para grafar a sonoridade desejada, em O cravo brigou com a rosa: arranjo didático (versões I e II), estabelecemos um paralelo entre a localização dos sons agudos na partitura (situados na região superior do pentagrama) e sua representação na parte superior do tampo do violão. Da mesma maneira, os sons graves (situados na região inferior do pentagrama) e sua representação na parte inferior do tampo do instrumento (Fig. 6). A execução se dá, respectivamente, por meio de golpe suave com o dedo polegar no cavalete (registro grave) e golpe suave com a palma da mão na parte superior do tampo (registro agudo), conforme o padrão rítmico da valsa brasileira (Fig. 7).

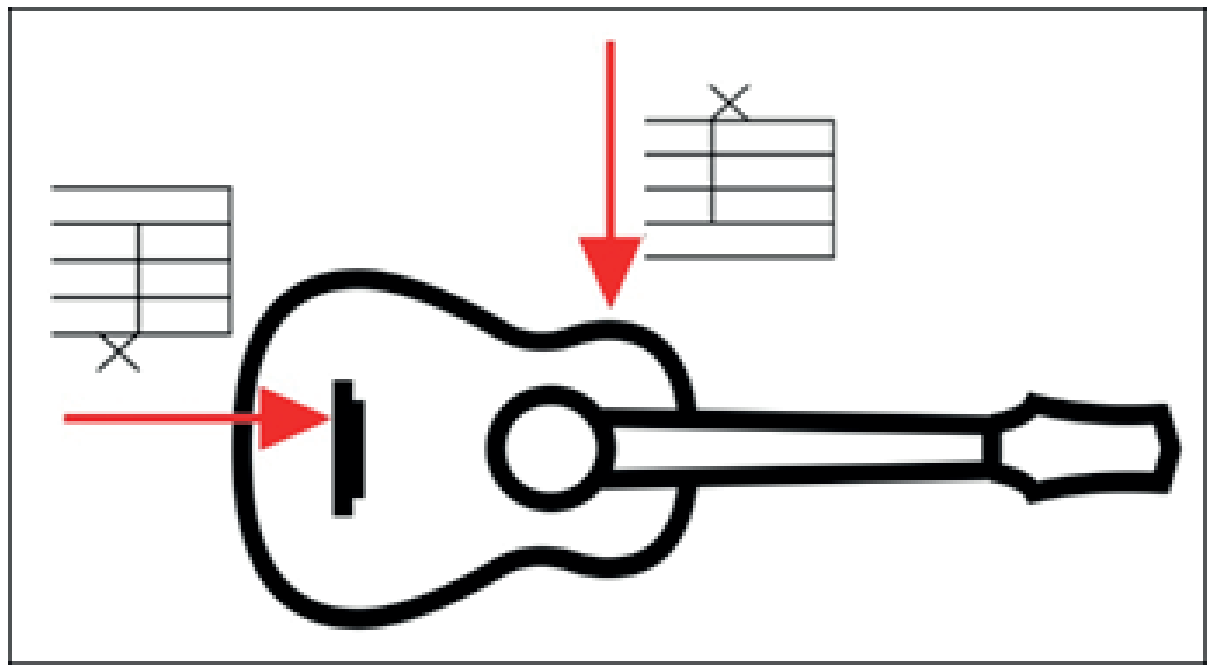

Fig. 6: Grafia de grave e agudo. Próximo ao cavalete, para se obter uma sonoridade no registro grave - grafada abaixo da última linha do pentagrama -, e, na lateral superior, para se obter uma sonoridade no registro agudo - grafada acima da última linha do pentagrama.

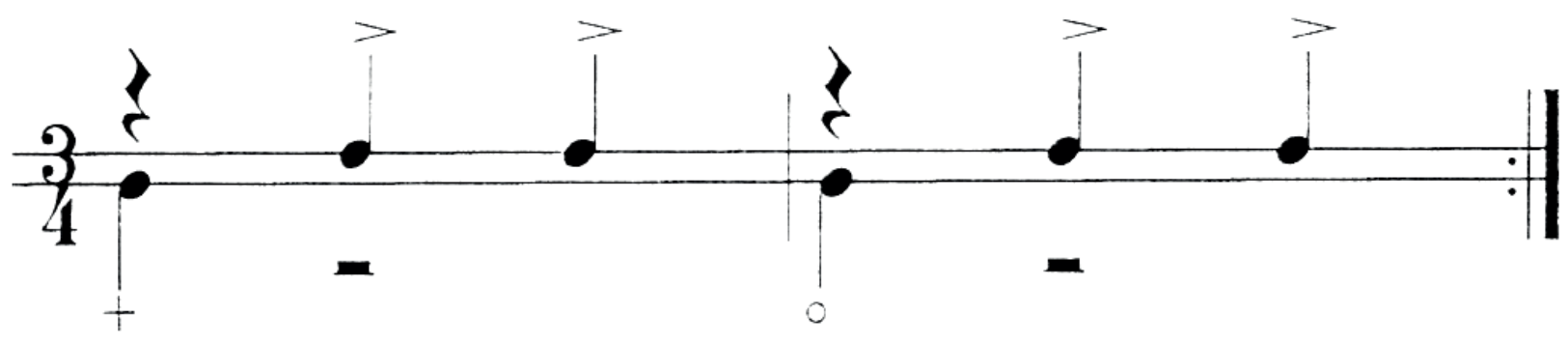

Fig. 7: Ritmo-padrão base da valsa brasileira (BOLÃO, 2010, p.129)

Em O cravo brigou com a rosa: arranjo didático (versões I e II), o nível intermediário pressupõe a habilidade de realizar a harmonia da peça, conforme uma fórmula rítmica determinada. Denominados genericamente como "levadas", tais padrões, recorrentes no âmbito do ensino do violão popular, implicam a leitura de cifras e contribuem para o desenvolvimento da percepção das funções harmônicas. Neste contexto, trabalhos como o de Becker (2013), por exemplo, são, ao mesmo tempo, um desdobramento e um complemento dos métodos práticos para violão. 
No caso de $O$ cravo brigou com a rosa: arranjo didático (versão I), para o nível intermediário, como base para a levada, reproduzimos o mesmo padrão do nível iniciante, porém definindo a voz grave, do baixo, e as vozes intermediárias. Os acordes foram escritos no pentagrama e acima foi colocada a cifra para identificá-los. Vale acrescentar que o modelo de levada pode ser extraído de trabalhos dirigidos ao violão, mas também de modelos apresentados em métodos direcionados aos estudantes de percussão.

Finalmente, pressupomos que o estudante do nível avançado seja capaz de executar as melodias propostas (Fig. 8). Aqui estão incluídos não somente aqueles que possuem conhecimentos de leitura musical, mas também aqueles que se dispõem a "tirar a melodia de ouvido". Assim, em O cravo brigou com a rosa: arranjo didático (versões I e II), a parte avançada contempla os estudantes que leem a música e aqueles que, desconhecendo o referencial gráfico (a partitura), podem executá-la de maneira intuitiva.

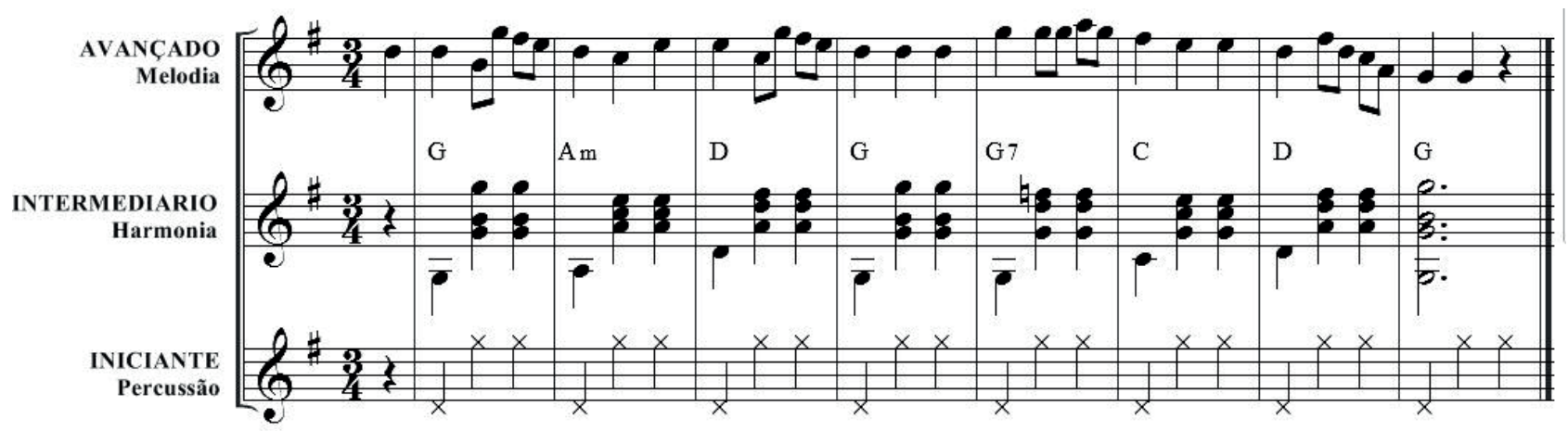

Fig. 8: O cravo brigou com a rosa: arranjo didático (versão l: 3 violões).

A partir desta proposta básica, não somente o professor, mas também os estudantes podem contribuir com novos elementos visando enriquecer os resultados obtidos. Uma segunda versão do arranjo de $O$ cravo brigou com a rosa: arranjo didático (versão II) inclui um contracanto para o nível avançado, dois executantes; uma fórmula rítmica complementar (arpejos) para o nível intermediário, dois executantes; além de inserir variações no modelo adotado na percussão para o nível iniciante, um executante (Fig. 9). Em ambas as propostas (versões I e II), recomendamos que, na medida do possível, os estudantes troquem de função, executando ora um ora outro nível. 


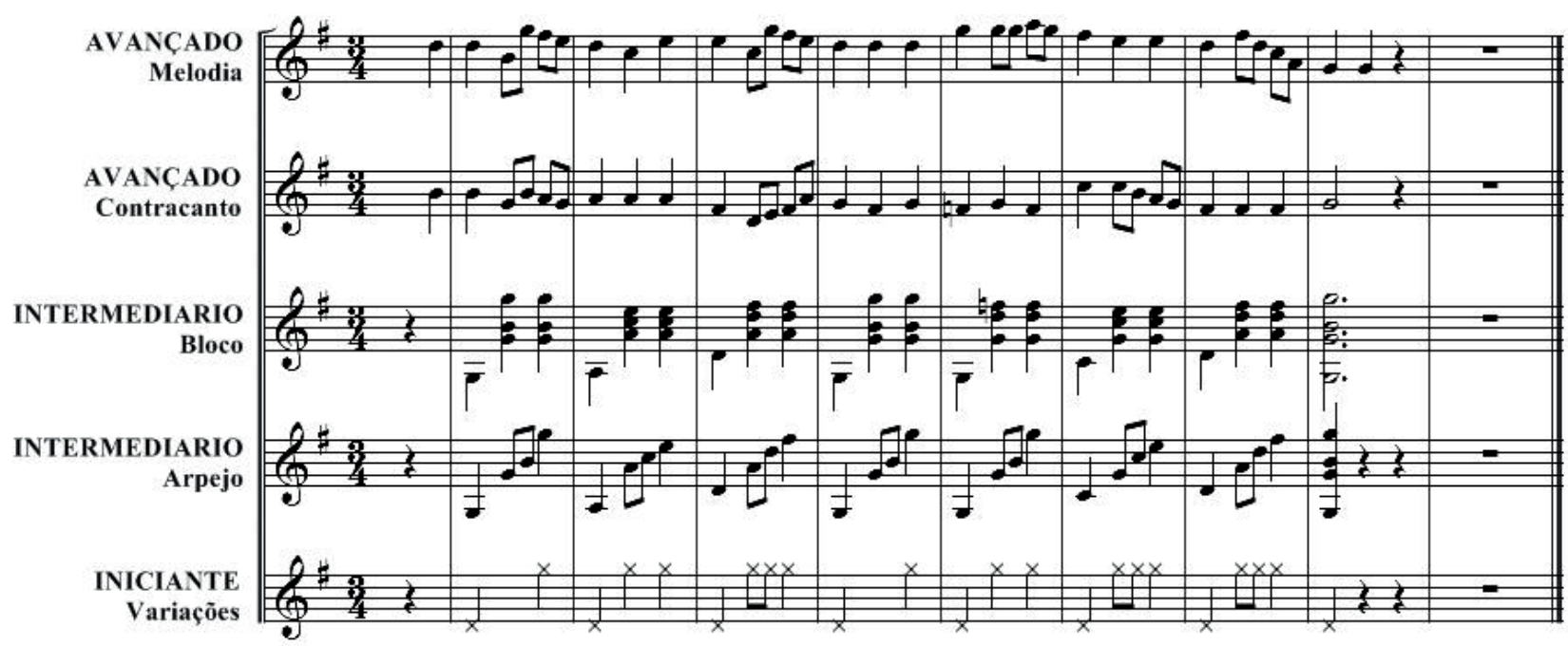

Fig. 9: O cravo brigou com a rosa: arranjo didático (versão II: 5 violões).

\section{Considerações finais}

No ano de 1799, foi publicado pelo compositor espanhol Fernando Ferandière (1750-1816) "o primeiro tratado a ensinar o guitarrista a ler música no pentagrama em vez de ensinar-lhe a tablatura" (DUDEQUE, 1994, p.53). Do século XIX, vieram os métodos que se consolidaram como os mais importantes para o desenvolvimento da técnica violonística, contribuindo para a ampliação do repertório e fazendo com que o instrumento começasse a ser comparado, por suas semelhanças e diferenças, com outros instrumentos. Neste contexto, o conjunto formado pelos trabalhos (métodos) aqui abordados representa uma pequena amostra das fases e correntes distintas da produção didático-pedagógica referente ao ensino do violão no Brasil.

Por exemplo, não foram examinados, entre outros, os trabalhos de Oswaldo Soares, A escola de Tárrega: método completo de violão (este volume contém desde os primeiros movimentos didáticos aos exercícios, lições, prelúdios e estudos dos mais célebres autores), escrito nos anos 1950, e, de Pedro Cameron, Estudo programado de violão: iniciação e 1o ano, escrito em 1978, cuja contribuição metodológica pode ser detectada em diversos trabalhos da atualidade. Neste sentido, aqui examinamos apenas o suficiente para esboçar o panorama onde a presente pesquisa se insere. A proposta de "arranjos didáticos" que apresentamos, de certa maneira, é decorrente desta linhagem de trabalhos, diferenciando-se pela ênfase na prática musical coletiva (música de câmara) e no uso de um repertório familiar aos estudantes (independentemente da corrente estética a que se filiam).

Para tal, estabelecemos uma estrutura básica (em três níveis), contemplando cada qual diferentes graus de conhecimento técnico e teórico. Desta maneira, exploramos recursos específicos (ostinatos e percussão), como ferramentas para introduzir os estudantes na leitura da partitura musical. Conforme Swanwick (1993, p.29), acreditamos que "um objetivo básico da educação musical é o desenvolvimento de uma apreciação rica e ampla quer o aluno se torne um músico profissional, um amador talentoso ou um 
membro sensível de plateias". Por outro lado, entendemos que o papel do professor de instrumento é estabelecer as condições necessárias para os estudantes terem experiência com o fazer musical através da performance de um repertório adequado do ponto de vista didático e sem restrições do ponto de vista estético.

\section{REFERÊNCIAS}

AFFONSO, Guilherme de Camargo Barros. A guitarra dos séculos XVII e XVIII em seus aspectos técnicos e estilístico-históricos através da tradução comentada e análise do Instruccion de musica sobre la guitarra española de Gaspar Sanz, 1697. 2015. Tese (Doutorado em Processos de Criação Musical) - Escola de Comunicações e Artes, Universidade de São Paulo, São Paulo, 2015. Disponível em: http://www.teses.usp.br/ teses/disponiveis/27/27158/tde-29102010-125844/pt-br.php. Acesso em: 14 jan. 2018.

ALFONSO, Sandra Mara. O violão, da marginalidade à academia: trajetória de Jodacil Damaceno. Uberlândia, MG: EDUFU, 2009.

ALMEIDA, Renato da Silva. Do intimismo à grandiloqüência: trajetória e estética do concerto para violão e orquestra: das raízes até a primeira metade do século XX em torno de Segovia e Heitor Villa Lobos. 2006. 167f. Dissertação (Mestrado em Musicologia) - USP - Escola de Comunicações e Artes, São Paulo, 2006. Disponível em: <http://www.teses.usp.br/teses/disponiveis/27/27140/tde-14082009-171602/pt-br. php>. Acesso em: 05 mar. 2019.

BARTOLONI, Giacomo. O violão na cidade de São Paulo no período de 1900 a 1950. 1995. 222f. Dissertação (Mestrado) - Universidade Estadual Paulista, Instituto de Artes, 1995. Disponível em: <http://hdl.handle.net/11449/99650>. Acesso em: 20 fev. 2019.

BECKER, Zé [José] Paulo. Levadas brasileiras para violão: samba, choro, bossa nova. 2 . ed. Rio de Janeiro: Edição do autor, 2013. (Livro, partituras e áudio on-line). 56p.

BELLINATI, Paulo. Jongo for 2 Guitars (1989). San Francisco: Guitar Solo Publications, 1993. 1 partitura (20 p.).

BERNARDINI, Attilio. Lições preparatórias: a nova técnica do violão (baseada na Escola de Tárrega). São Paulo: Irmãos Vitale, 1942. 22p.

BOLÃO, Oscar. Batuque é um privilégio. São Paulo: Irmãos Vitale, 2010. 161p.

CARDOSO, João Henrique Correa. A técnica violonística: um estudo das convergências e divergências nos métodos de ensino no decorrer da história do violão. 2015. 157 f. Dissertação (Mestrado em Música) - Universidade Federal de Goiás, 
Goiânia, 2015. Disponível em: https://repositorio.bc.ufg.br/tede/handle/tede/4769. Acesso em: 7 dez. 2018.

CARVALHO, Guilherme Paiva de. Música e literatura na sociedade de corte em transição. Revista dEsEnrEdoS, Teresina, n. 19, p. 2-20, 2013. Disponível em: http:// desenredos.dominiotemporario.com/doc/19-Artigo-SociedadeCorte-GuilhermePaiva. pdf. Acesso em: 12 jan. 2019.

CORREA, Adriano Palma. Sobre os "diagramas" no ensino do violão: uma introdução. 2015. 49 f. TCC (Graduação) - Curso de Licenciatura em Música, Educação Musical, Unirio, Rio de Janeiro, 2015.

DAMACENO, Jodacil Caetano; MACHADO, André Campos. Uma sugestão para iniciação ao violão. 2. ed. rev. Uberlândia: EDUFU, 2010. Caderno pedagógico. 114p.

DUDEQUE, Norton Eloy. História do violão. Curitiba: Ed. da UFPR, 1994. 113p. (Pesquisa n. 13)

FRANÇA, Cecília Cavalieri; SWANWICK, Keith. Composição, apreciação e performance na educação musical: teoria, pesquisa e prática. Em pauta, Rio de Janeiro, v. 13, n. 21, p. 5-41, 2002. Disponível em: https://seer.ufrgs.br/EmPauta/article/view/8526/4948. Acesso em: 9 mar. 2019.

HARDER, Rejane. Algumas considerações a respeito do ensino de instrumento: trajetória e realidade. Opus, Goiânia, v. 14, n. 1, p. 127-142, jun. 2008.

LIMA, Fanuel Maciel. A elaboração de arranjos de canções populares para violão solo. 200 f. Dissertação (Mestrado) - Instituto de Artes, Universidade Estadual de Campinas, 2003. Disponível em: http://repositorio.unicamp.br/handle/REPOSIP/284828. Acesso em: 14 mar. 2019.

MACHADO, André Campos. Minhas primeiras cordas. Uberlândia: EDUFU, 2007. 66p.

MARIANI, Silvana. O equilibrista das seis cordas: método de violão para crianças. 1. ed. rev. Curitiba: Editora UFPR, 2009. 131p.

MESQUITA, Tayro Louzeiro. Violão para criança: opinião de professores sobre métodos e materiais didáticos. 2015. 58 f. TCC (Graduação) - Curso de Licenciatura em Música, UnB, Brasília, 2015. Disponível em: http://bdm.unb.br/bitstream/10483/13067/1/2015_ TayroLouzeiroMesquita.pdf. Acesso em: 23 mar. 2019.

NICÁCIO, Ricardo Matias. Processos de musicalização: métodos de ensino do violão. 
In: JORNADA DE INICIAÇÃO CIENTÍFICA, 11., 2012, Rio de Janeiro. Semana de integração acadêmica, 15 a 21 de outubro de 2012. Rio de Janeiro: Unirio, 2012. p. 1-3. CD-ROM.

OLIVEIRA, Victor Matos. A escolha do repertório no ensino coletivo de instrumentos: uma experiência vivida no Projeto "Orquestra de Violões nas Escolas". Anais do SIMPOM, v. 3, n. 3, 2015.

OROSCO, Maurício Tadeu dos Santos. O compositor Isaias Sávio e sua obra para violão. 273 f. Tese (Doutorado) - Escola de Comunicação e Artes, Universidade de São Paulo, 2001. Disponível em: https://bdpi.usp.br/item/001211632. Acesso em: 20 fev. 2019.

PAZ, Ermelinda Azevedo. 500 canções brasileiras. Rio de Janeiro: Luiz Bogo Editor, 1989.

PINTO, Henrique. Iniciação ao violão: princípios básicos e elementares para principiantes. São Paulo: Ricordi, 1978. 63p.

PINTO, Henrique. Ciranda das seis cordas. São Paulo: Ricordi, 1985. 107p.

RICCIO, Maxwell. O violão entrou na roda: um guia prático para iniciantes. Rio de Janeiro: Irmãos Vitale, 2018. 72p.

ROCHA FILHO, Othon Gomes. da. Minhas primeiras notas ao violão. 9. ed. Rio de Janeiro: Irmãos Vitale, 1966. Volume 1. 99p.

SÁVIO, Isaías. Escola moderna do violão: técnica do mecanismo. Vol. 1. São Paulo: Ricordi, 1945. 55p.

Vamos estudar violão: iniciação. São Paulo: Ricordi, 1972. 14p.

SALUSTINO, José Joelson da Costa. Educação musical nos ambientes não formais: um olhar sob o Centro de Apoio à Criança. 2013. 46. Monografia (Graduação) - Curso de Licenciatura em Música, Educação Musical, UFRN, Natal, 2013.

SILVA, Priscilla Hygino Rodrigues da. Os métodos brasileiros de violão para público infantojuvenil e o ensino coletivo de violão na infância. 2013. 42 f. TCC (Graduação) Curso de Licenciatura em Música, Educação Musical, Unirio, Rio de Janeiro, 2013.

SWANWICK, Keith. Permanecendo fiel à música. In: ENCONTRO ANUAL DA ASSOCIAÇÃO BRASILEIRA DE EDUCAÇÃO MUSICAL, 2., 1993, Porto Alegre. Anais [...]. Porto Alegre, 1993, p. 19-32. 
Ensinando música musicalmente. São Paulo: Moderna, 2010. 128p., il., música; $23 \mathrm{~cm}$. (Formação e atuação em educação musical).

TEIXEIRA NETO, Moacyr. Música contemporânea brasileira para violão. Vitoria: Grafica e Editora A1, [199-]. 75p.

TOURINHO, Cristina. Ensino Coletivo de Instrumentos Musicais: crenças, mitos, princípios e um pouco de história. In: CONGRESSO REGIONAL DA ISME NA AMÉRICA LATINA; ENCONTRO ANUAL DA ABEM, 16., 2007, Campo Grande. Anais [...]. Campo Grande, 2007, p. 1-12. CD-ROM.

VASCONCELLOS, Daniel Murray Santana. Técnicas estendidas para violão: hibridização e parametrização de maneiras de tocar. 2013. 179 p. Dissertação (Mestrado) - Instituto de Artes, Universidade Estadual de Campinas, Campinas, SP. Disponível em: http:// www.repositorio.unicamp.br/handle/REPOSIP/285299. Acesso em: 24 ago. 2018.

VIEIRA, Gabriel; RAY, Sonia. Ensino coletivo de violão: técnicas de arranjo para o desenvolvimento pedagógico. In: CONGRESSO REGIONAL DA ISME NA AMÉRICA LATINA; ENCONTRO ANUAL DA ABEM, 16., 2007, Campo Grande. Anais [...]. Campo Grande, 2007, p. 1-12. CD-ROM.

ZANON, Fábio. O violão no Brasil depois de Villa-Lobos. Textos do Brasil. Vol. 12. Brasília: Ministério das Relações Exteriores, Assessoria de Comunicação Social, p. 7885, 2006. Disponível em: http://dc.itamaraty.gov.br/publicacoes/textos/portugues/ revista12.pdf. Acesso em: 7 fev. 2019. 